\title{
Anismus, Physiology, Radiology: Is It Time for Some Pragmatism? A Comparative Study of Radiological and Anorectal Physiology Findings in Patients With Anismus
}

\author{
Umberto Pisano ${ }^{1,2}$, Lesley Irvine ${ }^{3}$, Justina Szczachor ${ }^{4}$, Ahsin Jawad ${ }^{4}$, Andrew MacLeod ${ }^{5}$ Michael Lim ${ }^{4}$ \\ ${ }^{1}$ Department of General Sugery, Raigmore Hospital, Inverness; ${ }^{2}$ Department of Clinical and Interventional Radiology, Royal Victoria Hospital, \\ Belfast; Departments of ${ }^{3}$ Clinical Physiology, ${ }^{4}$ General Surgery, and ${ }^{5}$ Radiology, Raigmore Hospital, Inverness, United Kingdom
}

Purpose: Anismus is a functional disorder featuring obstructive symptoms and paradoxical contractions of the pelvic floor. This study aims to establish diagnosis agreement between physiology and radiology, associate anismus with morphological outlet obstruction, and explore the role of sphincteric pressure and rectal volumes in the radiological diagnosis of anismus.

Methods: Consecutive patients were evaluated by using magnetic resonance imaging proctography/fluoroscopic defecography and anorectal physiology. Morphological radiological features were associated with physiology tests. A categorical analysis was performed using the chi-square test, and agreement was assessed via the kappa coefficient. A Mann-Whitney test was used to assess rectal volumes and sphincterial pressure distributions between groups of patients. A P-value of $<0.05$ was significant.

Results: Forty-three patients ( 42 female patients) underwent anorectal physiology and radiology imaging. The median age was 54 years (interquartile range, 41.5-60 years). Anismus was seen radiologically and physiologically in 18 (41.8\%) and 12 patients (27.9\%), respectively. The agreement between modalities was $0.298(\mathrm{P}=0.04)$. Using physiology as a reference, radiology had positive and negative predictive values of $44 \%$ and $84 \%$, respectively. Rectoceles, cystoceles, enteroceles and pathological pelvic floor descent were not physiologically predictive of animus $(\mathrm{P}>0.05)$. The sphincterial straining pressure was $71 \mathrm{mmHg}$ in the anismus group versus $12 \mathrm{mmHg}$. Radiology was likely to identify anismus when the straining pressure exceeded $50 \%$ of the resting pressure $(\mathrm{P}=0.08)$.

Conclusion: Radiological techniques detect pelvic morphological abnormalities, but lead to overdiagnoses of anismus. No proctographic pathological feature predicts anismus reliably. A stronger pelvic floor paradoxical contraction is associated with a greater likelihood of detection by proctography.

Keywords: Anismus; Physiology; Radiology; Pelvic dyssynergia; Obstructive defecation

\section{INTRODUCTION}

The term Anismus, coined by Preston and Lennard-Jones in 1985

Received: August 19, 2016 - Accepted: September 22, 2016

Correspondence to: Umberto Pisano, M.D.

Department of General Sugery, Raigmore Hospital, Old Perth Road, IV2 3UJ,

Inverness, United Kingdom

Tel: +44-1463-705410, Fax: +44-1463-705606

E-mail: u.pisano@nhs.net

(C) 2016 The Korean Society of Coloproctology

This is an open-access article distributed under the terms of the Creative Commons Attribution NonCommercial License (http://creativecommons.org/licenses/by-nc/4.0) which permits unrestricted non-

commercial use, distribution, and reproduction in any medium, provided the original work is properly cited.
[1], defines a functional disorder with symptoms of obstruction and paradoxical movements of the pelvic floor muscles [2] (puborectalis and external anal sphincter muscles [3]). It has also been defined as an inappropriate contraction or inadequate relaxation of the pelvic floor muscle during defecation [4, 5]. Anismus is classified among all the other causes of outlet obstruction, whether they recognize an equally functional etiology (central nervous lesions, Chagas disease, and hereditary internal sphincter myopathy) or a morphological cause (rectocele, rectal prolapse, descending perineum syndrome, rectal tumor, etc.) [6].

Anismus combines functional constipation and pelvic dyssynergia. While the former can be evaluated by using established criteria $[4,5]$, pelvic dyssynergia can be assessed by using several diag- 
nostic tools; however, no universal consensus exists on how anismus should be detected (Table 1): While the vast majority of reports in the literature advocate the use of physiology tests rather than imaging techniques, the exact pattern that characterizes the disturbance on either manometry or electromyography (EMG) has not been unanimously agreed upon. Moreover, anorectal manometry potentially suffers from false-negative rates caused by displacement of the catheter and from false-positive results that are frequently caused by embarrassment of the patient [7]: a water-perfused catheter assembly [8] has been proven to induce artifacts and active anal contractions [9]. On the other hand, a solidstate catheter $[9,10]$ features the higher cost of permanent equipment and presents a potential infection control issue. Manometry alone is not sufficient according to some authors, who claim that an evacuation disorder should also be investigated with EMG: increased pressure recordings during defecation may be due to deficient relaxation of the internal sphincter, inappropriate contraction of the striated musculature, or a mixture of the two [11]. For this reason, needle EMG is advocated as essential because the surface EMG does not clearly differentiate the external anal sphincter from the puborectal muscle [11]. Nevertheless, needle EMG poses relevant challenges of patient compliance, infection, and possible artifacts, and its benefits in the evaluation of anismus have not been ascertained.

Alternative diagnostic tests increased in popularity when Halligan et al. [12] claimed that evacuating proctography (fluoroscopic imaging of barium paste evacuation) possessed a high positive predictive value (PPV) towards the diagnosis of anismus (identified as an evacuation time over 30 seconds [3]), which was confirmed with subsequent anorectal physiology testing. Dynamic magnetic resonance imaging (MRI) of the pelvis provides the additional advantage of not having to use any ionizing radiations and still provides free selection of planes, remarkable soft tissue imaging, and good temporal resolution: in such settings, anismus

Table 1. Previously used diagnostic criteria for anismus

\begin{tabular}{l}
\hline Manometric \\
The rectal pressure must increase ( $>50 \mathrm{mmH}_{2} \mathrm{O}$ ) on straining (failure to do so \\
would preclude a diagnosis of anismus) [21] \\
Increased anal canal pressure during straining [2] \\
Failure to expel a balloon [23, 24] \\
Electromyological \\
Demonstration of puborectalis recruitment $>50 \%$ during defecation [21] \\
Increased or insufficient ( $<20 \%$ ) decrease of activity [24] \\
Radiological \\
Absent opening of the anorectal angle during defecation (vs. 15-20 \\
expected) [13] \\
Long evacuation time (>30 sec) [3,12] \\
Failure to evacuate paste/rectal contrast or incomplete evacuation [6, 21] \\
\hline
\end{tabular}

has been defined as a failure of anorectal angle opening during straining [13] or a prolonged attempted defecation with incomplete evacuation [6]. Two-dimensional (2D) ultrasonography (US) and dynamic three-dimensional anorectal US [14] are being introduced, but the agreement between $2 \mathrm{D}$ echography and manometry is moderate $[2,15]$. While biofeedback has been shown to yield positive results in the treatment of anismus [16, 17], a consistent discrepancy exists between the diagnosis criteria and the methodologies that should be involved.

This pragmatic study has three aims: The first aim is to establish agreement between physiology and radiology in the diagnosis of anismus. The second is to ascertain whether an association exists between anismus and the anatomical causes of outlet obstruction diagnosed radiologically (rectocele, enterocele, cystocele, and pathological pelvic floor descent). The final aim is to explore the role of presphincteric pressure and rectal volumes in the physiological and the radiological diagnoses of anismus.

\section{METHODS}

Consecutive patients presenting with symptoms of obstructive defecation (confirmed via clinical history and physical examination) were evaluated prospectively by using sequential MRI proctography/fluoroscopic defecography and anorectal physiology testing. All suitable patients were recruited from those visiting the Outpatient Department at Raigmore Hospital, Inverness, United Kingdom, between the beginning of June 2013 and the end of January 2015. All patients underwent colonic evaluation to exclude obstructive pathology either via endoscopic examination or radiological assessment (computed tomography-colonography).

Patients underwent standard defecating proctography when symptoms of the posterior compartment were the predominant complaint. Those with multicompartmental involvement were more likely to undergo an MRI proctogram to assess the whole pelvic floor. Two consultant radiologists with a special gastrointestinal interest evaluated the images. T2W axial, sagittal and coronal sequences were obtained during pelvic floor contractions, valsalva maneuver and expulsion of $120 \mathrm{~mL}$ of gel previously introduced via the rectum. Patients with features of impaired evacuation on defecation (undergoing either fluoroscopy or MRI proctography) were defined by incapacity to expel the contrast and lack of anorectal angle widening during straining. Abnormal radiological features, such as rectoceles [18], cystoceles [6], enteroceles [6], and pathological pelvic floor descent [6], were likewise recorded. The presence of anismus on anorectal physiology investigations was compared with the same diagnosis made using radiological criteria.

The physiological assessment was carried out using a Gaeltec CTR/L-3 solid-state manometry catheter (IV55 8GU, Gaeltec Devices Ltd., Dunvegan, Isle of Skye, UK). Three circumferential pressure sensors were positioned in the high-pressure zone in the anal canal with a balloon sited in the rectum; the balloon was in- 
flated with sufficient air to elicit a recto-anal inhibitory response and for the patient to perceive a sensation of rectal filling. The balloon expulsion test involved asking the patient to push down against the balloon as if they were trying to expel it; they were asked to have a minimum of three attempts. Any decrease in pressure from the baseline resting pressure was deemed a normal response; if two out of the three attempts showed a relaxation, anismus was excluded. Included in the assessment was a surface EMG (Neuropack EP/EMG measuring system, Nihon Kohden, Tokyo, Japan) with the surface EMG electrodes positioned at the anal verge. An EMG reading was taken "at rest", when "pulling-up" and when "bearing-down": an increase in EMG activity when bearing down was taken as an indication of pelvic floor dyssynergia. Anismus was diagnosed after consistent findings from manometry and EMG combined (Table 2). The physiology testing was performed in a blind-manner from the imaging studies. The abnormal radiological features previously described were then associated with anismus on anorectal physiology.

Data were nonparametric. A categorical analysis was performed using the chi-square or the Fisher test while agreement was as-

Table 2. Crosstabulation of physiological and radiological diagnoses of anismus

\begin{tabular}{lccc}
\hline \multirow{2}{*}{ Physiological anismus $^{\mathrm{a}}$} & \multicolumn{3}{c}{ Radiological anismus $^{\mathrm{b}}$} \\
\cline { 2 - 4 } & Present & Absent & Total \\
\hline Present & 8 & 4 & 12 \\
Absent & 10 & 21 & 31 \\
Total & 18 & 25 & 43 \\
\hline
\end{tabular}

Kappa agreement $=0.298, P=0.04$.

alncapacity to expel the contrast and lack of anorectal angle widening during straining. IIncreased pressure or failure of relaxation on manometry and increased electromyography activity during straining. sessed using the kappa coefficient. A Mann-Whitney U-test was employed to assess the distribution of rectal volumes and presphincterial pressures among participants suffering from anismus and the other participants. A P-value of $<0.05$ was considered to be statistically significant.

\section{RESULTS}

Forty-three patients ( 42 female patients) underwent both anorectal physiological and radiologic examinations for suspected anismus. The median age was 54 years (interquartile range, 41.5-60 years). Thirty of the 43 patients underwent MRI (69.7\%). Anismus was diagnosed in 18 patients $(41.8 \%$ ) by using imaging but in only 12 patients $(27.9 \%)$ by using anorectal physiology (Table 2). Only fair agreement was noted between physiology and radiology (kappa $=0.298, \mathrm{P}=0.04$ ) for diagnosing anismus. When manometry/EMG testing was adopted as the reference standard, radiological tests were found to have a PPV of $44 \%$ and a negative predictive value of $84 \%$.

Table 3 lists the abnormal radiological findings seen on proctography. No radiological abnormalities seen on fluoroscopy or MRI (rectoceles $[P=0.1]$, cystoceles $[P=0.16]$, enteroceles $[P=1.0]$, and pathological pelvic floor descent $[\mathrm{P}=0.24]$ ) could consistently predict the presence of anismus based on physiology. Of the 12 patients with anismus, only 1 was found to have an inadequate relaxation of the sphincter during defecation. The remaining 11 patients (25.5\%) displayed a pattern of paradoxical contraction (Fig. 1). Overall, the sphincterial pressure during straining was found to feature a median of $71 \mathrm{mmHg}$ in the anismus group versus only $12 \mathrm{mmHg}$ in the other group. An interesting trend for radiology was that it picked up anismus when the straining pressure exceeded $50 \%$ of the resting sphincterial pressure $(\mathrm{P}=0.08)$ (Table 4).

Table 3. Demographic data, radiological morphological abnormalities, and physiological test results for the participants

\begin{tabular}{|c|c|c|c|c|}
\hline Variable & Anismus $^{\mathrm{a}}$ & Nonanismus $^{b}$ & Total & P-value \\
\hline Age & $49.5(41-57.75)$ & $55(42-61)$ & $54(41-54)$ & 0.62 \\
\hline Previous surgery & $3(18.8)$ & $13(81.2)$ & $16(37.2)$ & 0.49 \\
\hline Rectocele & $6(19.4)$ & $25(80.6)$ & $31(72.1)$ & 0.1 \\
\hline Enterocele & $1(25)$ & $3(75)$ & $4(9.3)$ & 1.0 \\
\hline Cystocele & $2(12.5)$ & $14(87.5)$ & $16(37.2)$ & 0.16 \\
\hline Pelvic floor descent & $9(23.7)$ & $29(76.3)$ & $38(88.4)$ & 0.24 \\
\hline 1st sensation volume & $20(15-25)$ & $20(15-26.25)$ & $20(15-25)$ & 0.94 \\
\hline Urge volume & $50(36.2-97.5)$ & $50(45-75)$ & $50(40-80)$ & 0.95 \\
\hline Max tolerable volume & $117.5(78.75-181.25)$ & $125(80-145)$ & $125(80-150)$ & 0.49 \\
\hline Baseline sphincteric pressure & $32(24.5-54.25)$ & $31(23-40)$ & $31(23-49)$ & 0.48 \\
\hline Straining sphincteric pressure & $71(47.25-86.75)$ & $12(-1-16)$ & $16(4-44)$ & $<0.001$ \\
\hline
\end{tabular}

Values are resented as median (interquartile range) or number (\%). Mann-Whitney U-test.

${ }^{\mathrm{a}, \mathrm{b}} \mathrm{Anismus}$ as defined by physiological criteria. 


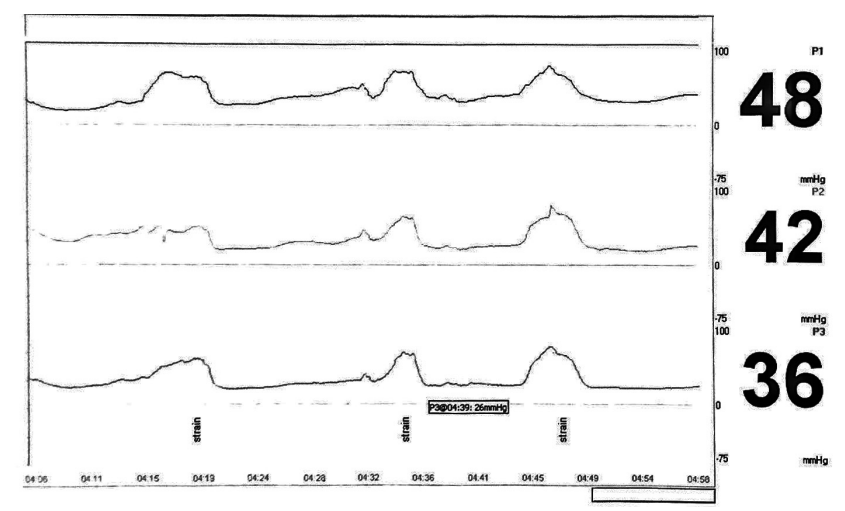

Fig. 1. Manometric pattern of an individual diagnosed with anismus in the study.

\section{DISCUSSION}

As anismus is a functional disorder, physiological testing should represent the gold standard $[12,19]$ despite concerns about using manometry alone [7]. Rao et al. [20] identified 3 different manometric patterns of dyssynergia; however, if one is to adopt Robert et al's [21] criteria, the so-called type II should not be named anismus due to an inadequate level of intrarectal pressure on straining. As rectal pressures were not recorded in the current study at the time of manometry, patients were categorized into either a "paradoxical" or a "failure of relaxation" group (types 1 and 3, according to Rao et al. [20]). The majority of our patients displayed a pattern of paradoxical contraction rather than failure of relaxation; nevertheless, they demonstrated a good responsiveness to biofeedback therapy. Rectal pressure was not assessed in this study, and we believe that in order to diagnose anismus, an abnormal pattern of the sphincter activity during defecation already provides significant information.

From a radiological point of view, a proctographic assessment has a tendency to overdiagnose anismus $[3,19]$ partly because no widely agreed upon diagnostic criteria exist. Additionally, proctography requires patients to be in a nonphysiological position: defecation in an unfamiliar environment leads to a lack of privacy and to performance anxiety in the presence of total strangers. In our sample of patients, no correlation was noted between morphological abnormalities on proctograms and a physiological diagnosis of anismus, although structural pelvic floor anomalies have been shown to be associated with muscle coordination dysfunction [22]. Our PPV associated with radiological testing reflects a high number of false positives, which justifies the use of the term "radiological pseudoanismus" in other studies [19]. We emphasize that radiological assessment in isolation without manometric assessment in patients with symptoms of obstructed defecation may lead to an overdiagnosis of anismus. Combined physiological testing should identify dyssynergia more accurately and may accordingly have an impact on management decisions.
Table 4. Crosstabulation of patients with anismus according to the change in sphincteric pressure on straining

\begin{tabular}{lccc}
\hline \multirow{2}{*}{ Sphincteric straining pressure increase } & \multicolumn{3}{c}{ Radiological anismus } \\
\cline { 2 - 4 } & Present & Absent & Total \\
\hline$<50 \%$ & 1 & 3 & 4 \\
$\geq 50 \%$ & 6 & 1 & 7 \\
Total & 7 & 4 & 11 \\
\hline
\end{tabular}

Fisher exact test. $P=0.08$.

In our experience, agreement between radiology and physiology may be viewed from a quantitative perspective. In essence, the greater the change in sphincteric pressure between baseline and straining, the more likely proctography will unveil an underlying anismus. Our findings sustain the idea that an anorectal measurement is likely to lead to a more conservative approach towards a functional disorder, and our aim was to initiate a discussion on whether patients with obstructive defecation should first be examined via anorectal physiology; in the absence of anismus, an additional radiological assessment would identify and stratify the extent of morphological consequences from such a disorder.

A physiology assessment might be prone to a variable rate of false negatives if the sensors migrate during bearing down; however we feel that this issue can be addressed by experienced technicians and by repeated attempts on routine testing. We also acknowledge that hypothetically a reverse interpretation of results could be adopted: one cannot exclude that patients with radiological anismus, rather than their being false positives, might simply have been diagnosed at an earlier stage of their functional disorder. Follow-up on these groups of patients with further clinical and physiological assessments longi- tudinally would be interesting.

This project aimed to cast additional light on anismus as an entity and to fill the gap between physiology and radiology. Although a new point for discussion has arisen, this pragmatic study features a small number of patients. Additional data are being gathered prospectively to confirm the trends noted during the study. In conclusion, radiological techniques are useful to document morphological abnormalities associated with outlet obstruction, but may be associated with an overdiagnosis of anismus. Radiological tests should not be used solely to investigate patients with this condition. Our study has demonstrated a suboptimal agreement of physiologic testing and radiology in the diagnosis of anismus. No morphological abnormality on proctography was found to be significantly associated with pelvic floor dyssynergia. Last, but not least, a major finding of this research appears to be that the stronger the paradoxical contraction of the pelvic floor is, the more likely it is to be correctly identified on proctography.

\section{CONFLICT OF INTEREST}

No potential conflict of interest relevant to this article was reported. 


\section{REFERENCES}

1. Preston DM, Lennard-Jones JE. Anismus in chronic constipation. Dig Dis Sci 1985;30:413-8.

2. Murad-Regadas SM, Regadas FS, Barreto RG, Rodrigues LV, Fernandes GO, Lima DM. Is dynamic two-dimensional anal ultrasonography useful in the assessment of anismus? A comparison with manometry. Arq Gastroenterol 2010;47:368-72.

3. Hompes R, Harmston C, Wijffels N, Jones OM, Cunningham C, Lindsey I. Excellent response rate of anismus to botulinum toxin if rectal prolapse misdiagnosed as anismus ('pseudoanismus') is excluded. Colorectal Dis 2012;14:224-30.

4. Drossman DA. The functional gastrointestinal disorders and the Rome II process. Gut 1999;45 Suppl 2:II1-5.

5. Drossman DA. The functional gastrointestinal disorders and the Rome III process. Gastroenterology 2006;130:1377-90.

6. Bolog N, Weishaupt D. Dynamic MR imaging of outlet obstruction. Rom J Gastroenterol 2005;14:293-302.

7. Smout AJ. Manometry of the gastrointestinal tract: toy or tool? Scand J Gastroenterol Suppl 2001;(234):22-8.

8. Hill JR, Kelley ML Jr, Schlegel JF, Code CF. Pressure profile of the rectum and anus of healthy persons. Dis Colon Rectum 1960;3: 203-9.

9. Savoye G, Leroi AM, Bertot-Sassigneux P, Touchais JY, Devroede G, Denis P. Does water-perfused catheter overdiagnose anismus compared to balloon probe? Scand J Gastroenterol 2002;37:1411-6.

10. Arhan P, Faverdin C. Une sonde a ballonnets pour l'etude de la mecanique anorectale. Pathol Biol. 1972;20:191-4.

11. Jost WH, Schrank B, Herold A, Leiss O. Functional outlet obstruction: anismus, spastic pelvic floor syndrome, and dyscoordination of the voluntary sphincter muscles. Definition, diagnosis, and treatment from the neurologic point of view. Scand J Gastroenterol 1999;34:449-53.

12. Halligan S, Malouf A, Bartram CI, Marshall M, Hollings N, Kamm MA. Predictive value of impaired evacuation at proctography in diagnosing anismus. AJR Am J Roentgenol 2001;177:633-6.

13. Martín Martín G, García Armengol J, Roig Vila JV, García Coret MJ, Martínez Sanjuán V, Almela Notari P, et al. Analysis of experience in the use of dynamic pelvic magnetic resonance imaging in the assessment of obstructive defaecation syndrome. Cir Esp 2012;90:292-7.
14. Murad-Regadas SM, Regadas Filho FS, Regadas FS, Rodrigues LV, de J R Pereira J, da S Fernandes GO, et al. Use of dynamic 3-dimensional transvaginal and transrectal ultrasonography to assess posterior pelvic floor dysfunction related to obstructed defecation. Dis Colon Rectum 2014;57:228-36.

15. Regadas FS, Haas EM, Abbas MA, Marcio Jorge J, Habr-Gama A, Sands D, et al. Prospective multicenter trial comparing echodefecography with defecography in the assessment of anorectal dysfunction in patients with obstructed defecation. Dis Colon Rectum 2011;54:686-92.

16. Ahadi T, Madjlesi F, Mahjoubi B, Mirzaei R, Forogh B, Daliri SS, et al. The effect of biofeedback therapy on dyssynergic constipation in patients with or without Irritable Bowel Syndrome. J Res Med Sci 2014;19:950-5.

17. Solomon MJ, Pager CK, Rex J, Roberts R, Manning J. Randomized, controlled trial of biofeedback with anal manometry, transanal ultrasound, or pelvic floor retraining with digital guidance alone in the treatment of mild to moderate fecal incontinence. Dis Colon Rectum 2003;46:703-10.

18. Carter D, Gabel MB. Rectocele--does the size matter? Int J Colorectal Dis 2012;27:975-80.

19. Lindsey I, Nugent K, Dixon T, editors. Pelvic floor disorders for the colorectal surgeon. Oxford: Oxford University Press; 2011;.

20. Rao SS, Mudipalli RS, Stessman M, Zimmerman B. Investigation of the utility of colorectal function tests and Rome II criteria in dyssynergic defecation (Anismus). Neurogastroenterol Motil 2004; 16:589-96.

21. Roberts JP, Womack NR, Hallan RI, Thorpe AC, Williams NS. Evidence from dynamic integrated proctography to redefine anismus. Br J Surg 1992;79:1213-5.

22. Karlbom U, Påhlman L, Nilsson S, Graf W. Relationships between defecographic findings, rectal emptying, and colonic transit time in constipated patients. Gut 1995;36:907-12.

23. Fleshman JW, Dreznik Z, Cohen E, Fry RD, Kodner IJ. Balloon expulsion test facilitates diagnosis of pelvic floor outlet obstruction due to nonrelaxing puborectalis muscle. Dis Colon Rectum 1992;35:1019-25.

24. Schouten WR, Briel JW, Auwerda JJ, van Dam JH, Gosselink MJ, Ginai AZ, et al. Anismus: fact or fiction? Dis Colon Rectum 1997; 40:1033-41. 